\title{
Co-infection with Angiostrongylus chabaudi and Dirofilaria immitis in a wildcat, Felis silvestris from Romania - a case report
}

\author{
Călin Mircea Gherman ${ }^{1}$, Angela Monica Ionică ${ }^{1}$, Georgiana Deak $^{1}$, \\ Gabriel Bogdan Chișamera², Andrei Daniel Mihalca ${ }^{1}$
}

\begin{abstract}
${ }^{1}$ University of Agricultural Sciences and Veterinary Medicine Cluj-Napoca, Faculty of Veterinary Medicine, Department of Parasitology and Parasitic Diseases, Cluj-Napoca, Romania

${ }^{2}$ National Museum of Natural History "Grigore Antipa", Bucharest, Romania
\end{abstract}

Received March 1, 2019

Accepted June 13, 2019

\begin{abstract}
Dirofilaria immitis is a worldwide spread nematode affecting the pulmonary artery and the heart of dogs (rarely reported in cats), especially in areas where the dogs show a high prevalence of infection. Angiostrongylus chabaudi is, in turn, a cardiopulmonary nematode of felids identified in several southern European countries and Germany. Co-infections of Dirofilaria immitis and Angiostrongylus spp. are known only in canids. We report a case of D. immitis and A. chabaudi co-infection in a road-killed wildcat originating from Southeastern Romania. Overall, 17 nematodes were collected from the pulmonary arteries of the wildcat and were morphologically identified as $A$. chabaudi ( 2 males and 15 females). Another nematode was collected from the right ventricle and identified as adult male $D$. immitis. Genomic DNA was extracted from one nematode of each of the two species and a fragment of the cox 1 gene was amplified and sequenced. The sequences obtained from the nematodes showed $100 \%$ similarity to a sequence of $A$. chabaudi isolated from Romania (Accession number KU521521) and to various D. immitis sequences from Europe, Asia and Australia (e.g. KT716014, EU159111, AJ537512). This is the first report of $A$. chabaudi and D. immitis co-infection in a felid, revealing the possibility of similar situations in domestic cats. This requires a more in-depth clinical and laboratory examination of animals with respiratory and cardiac symptoms.
\end{abstract}

Wildlife, lungworms, feline parasitology

The wildcat, Felis silvestris is a small feline found in the Old World characterized by a broad diet that includes micromammals, birds, fish, reptiles, arthropods, and gastropods (Lanszki et al. 2016), making it susceptible to the infection with a wide variety of parasites (Krone et al. 2008). Moreover, their crepuscular and nocturnal lifestyle exposes wildcats to mosquito bites. Among the parasitic diseases, cardio-pulmonary nematodes can cause severe diseases in both domestic and wild felids worldwide. Several species of cardiorespiratory parasites have been found in felids, including Aelurostrongylus abstrusus, Troglostrongylus brevior, T. subcrenatus, Eucoleus aerophilus, Angiostrongylus chabaudi, and Dirofilaria immitis reported from various regions and with variable prevalence (Traversa and Di Cesare 2014).

Angiostrongylus chabaudi is a snail-borne nematode localized in the pulmonary arteries and right heart of domestic and wild cats and has a limited geographic distribution: Italy (Biocca 1957; Traversa et al. 2015), Germany (Steeb et al. 2014), Greece (Diakou et al. 2016), Romania (Gherman et al. 2016), and Bulgaria (Giannelli et al. 2016). The filarioid mosquito-borne nematode $D$. immitis infects the heart and pulmonary arteries of carnivores, primarily canids, but it is rarely reported in cats (McCall et al. 2008). Its limited occurrence in cats has been explained mainly by the enhanced host resistance, most of the infections being recorded mainly in hyper-endemic regions where about $10-25 \%$ of the dogs are infected (Venco et al. 2011).

Address for correspondence:

Georgiana Deak

Department of Parasitology and Parasitic Diseases

Faculty of Veterinary Medicine

University of Agricultural Sciences and Veterinary Medicine Cluj-Napoca

Calea Mănăștur 3-5, 400372, Cluj-Napoca, 400372, Romania

Phone: +40 745269718

E-mail: georgiana.deak@usamvcluj.ro

http://actavet.vfu.cz/ 
Co-infections of D. immitis and Angiostrongylus spp. are rarely reported in carnivores. Such co-infections are known only in canids in which $D$. immitis - Angiostrongylus vasorum co-infections were reported in domestic dogs in Portugal (Alho et al. 2014) and Italy (Del Prete et al. 2015; Di Cesare et al. 2015), and in a golden jackal in Serbia (Gavrilović et al. 2017). To our knowledge, so far there have been no reported co-infections by $D$. immitis and A. chabaudi in felids, a situation which we report in the current paper.

\section{Case presentation}

A road-killed male wildcat was collected in Soveja $\left(45.9919795^{\circ} \mathrm{N} ; 26.6358592^{\circ} \mathrm{E}\right)$, Vrancea County, Romania. The body was necropsied, and parasites located in the right ventricle and the pulmonary arteries were preserved in formalin for morphological characterization, and in ethanol for molecular analysis. The species was identified using morphological keys and descriptions (Biocca 1957; Costa et al. 2003; Furtado et al. 2010). For further confirmation of the species identification, molecular tools were also used. Genomic DNA was extracted from both species of nematodes (one individual from each), using a commercial kit (Isolate II Genomic DNA Kit, Bioline, UK). The molecular characterization was performed by PCR amplification of a portion of the cox 1 gene. For A. chabaudi, a $710 \mathrm{bp}$ fragment was amplified using the universal invertebrate primer pair, LCO1490/HCO2198, as previously described (Folmer et al. 1994). For D. immitis, a $670 \mathrm{bp}$ portion was amplified using the Spirurida-specific NTF/NTR primer pair, according to previously published protocols (Casiraghi et al. 2001). The amplicons were submitted to direct sequencing, using an external service (Macrogen Europe).

Overall, 18 nematodes were collected from the pulmonary arteries and the right ventricle of the wildcat (Plate III, Fig.1). Of these, one nematode was identified as adult male D. immitis and 17 specimens were identified as $A$. chabaudi ( 2 males and 15 females). In the case of $A$. chabaudi females, the body (18.3-23.5 mm length, $0.245-0.296 \mathrm{~mm}$ width) had a barber-pole aspect. The males (14.5-15.0 mm length; 0.189-0.221 mm width) were uniformly coloured and had a small copulatory bursa with two symmetrical lateral lobes and a poorly developed dorsal lobe. All the features were in line with previous morphological descriptions of the species (Biocca 1957; Gherman et al. 2016; Diakou et al. 2016). The male $D$. immitis (142.6 $\mathrm{mm}$ in length; $0.43 \mathrm{~mm}$ in width) had a spiralled posterior end with a smooth cuticle, except the caudal extremity, which presented parallel cuticular ridges. Two unequal spicules were present on the lower curvature, the larger one $(0.35 \mathrm{~mm})$ placed in a canal of the smaller one $(0.18 \mathrm{~mm})$. The paired and unpaired pre-, ad-, and post-papillae were also visible. All other characteristics were in accordance with the known features of the species (Furtado et al. 2010).

The sequence obtained from the nematodes morphologically identified as $A$. chabaudi showed $100 \%$ similarity to a sequence of $A$. chabaudi previously isolated from Romania (Accession number KU521521). Similarly, the sequence obtained from the nematode morphologically identified as $D$. immitis showed $100 \%$ similarity to various $D$. immitis sequences from Europe, Asia and Australia (KT716014, EU159111, AJ537512).

\section{Discussion}

Both species identified in this study are generally rarely reported in felids. Dirofilaria immitis, a typical canine parasite, has been previously reported in wildcats only in Serbia (Penezić et al. 2014) and Romania (Ionică et al. 2017). In domestic cats, the reports are also scarce, and found mainly in areas where prevalence of the infection in dogs is high (McCall et al. 2008). The scarcity of D. immitis reports in felids was explained by the poor suitability of cats as definitive hosts (McCall et al. 1992). In cats, only 
a small percentage of worms become adults and their lifespan in no longer than 2-4 years, with most worms dying before reaching maturity (McCall et al. 2008). Although microfilariaemia is uncommon in infected cats, DNA of microfilarial origin was found in one out of ten wildcats examined in Romania (Ionică et al. 2017). Another hypothesis for the low prevalence of $D$. immitis in felids is related to the feeding preferences of the mosquito vectors (Labarthe et al. 1998). On the other hand, for A. chabaudi, a typical felid parasite, the scarcity of reports is probably related to misidentification of faecal larvae with other lungworm species or to poor surveillance (Gherman et al. 2016).

The wildcat from this case report originated from Vrancea County, Southeastern Romania. To date, no infection with $D$. immitis was found in this county in dogs or wild canids, but there have been reports of infection in other canids in neighbouring counties (Ionică et al. 2017). No information is available about the natural gastropod hosts of A. chabaudi. Recently, Cornu aspersum snails have been experimentally confirmed as a suitable intermediate host for $A$. chabaudi (Colella et al. 2017). However, gastropods are rarely part of the wildcats' diet (Lanszki et al. 2016), suggesting that their infection with $A$. chabaudi could be, as in the case of $A$. vasorum (Spratt 2015), related to the consumption of paratenic hosts (i.e. birds, reptiles or amphibians).

Generally, co-infections are known to be more clinically severe than mono-infections. The clinical importance of co-infections with cardiopulmonary nematodes in cats was highlighted by Traversa et al. (2015) who diagnosed a domestic cat infected with three nematode species: A. abstrusus, T. brevior, and A. chabaudi. This is also the only description of the clinical presentation of an animal infected with $A$. chabaudi. To the best of our knowledge, this is the first report of $A$. chabaudi and D. immitis co-infection in a felid and highlights the possibility of similar situations in domestic cats, which requires a more in-depth clinical and laboratory examination of animals with respiratory and cardiac symptoms.

\section{References}

Alho A, Schnyder M, Meireles J, Belo S, Deplazes P, Madeira de Carvalho L 2014: Preliminary results on the seroprevalence of Angiostrongylus vasorum and co-infection with Dirofilaria immitis in shelter dogs from Portugal. Parasit Vectors 7 (Suppl 1): O26

Biocca E 1957: Angiostrongylus chabaudi n. sp., parassita del cuore e dei vasi polmonari del gatto selvatico (Felis silvestris). Lincei - Rend Sc Fis Mat Nat 22: 526-532

Casiraghi M, Anderson TJ, Bandi C, Bazzocchi C, Genchi C 2001: A phylogenetic analysis of filarial nematodes: comparison with the phylogeny of Wolbachia endosymbionts. Parasitology 122: 93-103

Colella V, Cavalera MA, Deak G, Tarallo VD, Gherman CM, Mihalca AD, Otranto D 2017: Larval development of Angiostrongylus chabaudi, the causative agent of feline angiostrongylosis, in the snail Cornu aspersum. Parasitology 144: 1922-1930

Costa JO, De Araujo Costa HM, Guimaraes MP 2003: Redescription of Angiostrongylus vasorum (Baillet, 1866) and systematic revision of species assigned to the genera Angiostrongylus Kamensky, 1905 and Angiocaulus Schulz, 1951. Rev Méd Vét 154: 9-16

Del Prete L, Maurelli MP, Pennacchio S, Bosco A, Musella V, Ciuca L, Cringoli G, Rinaldi L 2015: Dirofilaria immitis and Angiostrongylus vasorum: the contemporaneous detection in kennels. BMC Vet Res 11: 305

Di Cesare A, Traversa D, Manzocchi S, Meloni S, Grillotti E, Auriemma E, Pampurini F, Garofani C, Ibba F, Venco L 2015: Elusive Angiostrongylus vasorum infections. Parasit Vectors 8: 438

Diakou A, Psalla D, Migli D, Di Cesare A, Youlatos D, Marcer F, Traversa D 2016: First evidence of the European wildcat (Felis silvestris silvestris) as definitive host of Angiostrongylus chabaudi. Parasitol Res 115: 1235-1244

Folmer O, Black M, Hoeh W, Lutz R, Vrijenhoek R 1994: DNA primers for amplification of mitochondrial cytochrome c oxidase subunit I from diverse metazoan invertebrates. Mol Mar Biol Biotechnol 3: 294-299

Furtado AP, Melo FT, Giese EG, dos Santos JN 2010: Morphological redescription of Dirofilaria immitis. J Parasitol 96: 499-504

Gavrilović P, Marinković D, Todorović I, Gavrilović A 2017: First report of pneumonia caused by Angiostrongylus vasorum in a golden jackal. Acta Parasitol 62: 880-884

Gherman CM, Ionică AM, D’Amico G, Otranto D, Mihalca AD 2016: Angiostrongylus chabaudi (Biocca, 1957) in wildcat (Felis silvestris silvestris, S) from Romania. Parasitol Res 115: 2511-2517 
Giannelli A, Kirkova Z, Abramo F, Latrofa MS, Campbell B, Zizzo N, Cantacessi C, Dantas-Torres F, Otranto D 2016: Angiostrongylus chabaudi in felids: new findings and a review of the literature. Vet Parasitol 228: 188-192

Ionică AM, Matei IA, D’Amico G, Ababii J, Daskalaki AA, et al. 2017: Filarioid infections in wild carnivores: a multispecies survey in Romania. Parasit Vectors 10: 332

Krone O, Guminsky O, Meinig H, Herrmann M, Trinzen M, Wibbelt G 2008: Endoparasite spectrum of wild cats (Felis silvestris Schreber, 1777) and domestic cats (Felis catus L.) from the Eifel, Pfalz region and Saarland, Germany. Eur J Wildl Res 54: 95-100

Labarthe N, Serrão ML, Melo YF, de Oliveira SJ, Lourenço-de-Oliveira R 1998: Mosquito frequency and feeding habits in an enzootic canine dirofilariasis area in Niterói, state of Rio de Janeiro, Brazil. Mem Inst Oswaldo Cruz 93: $145-154$

Lanszki J, Kletečki E, Trócsányi B, Mužinić J, Széles GL, Purger JJ 2016: Feeding habits of house and feral cats (Felis catus) on small Adriatic islands (Croatia). North-West J Zool 12: 336-348

McCall JW, Dzimianski MT, McTier TL, Jernigan AD, Jun JJ, Mansour AE, Supakorndej P, Plue RE, Clark JN, Wallace DH, Lewis RE 1992: Biology of experimental heartworm infection in cats. In: Soll MD (Ed.): Proceedings of the Heartworm Symposium '92. Batavia, IL: American Heartworm Society, pp. 71-79

McCall JW, Genchi C, Kramer LH, Guerrero J, Venco L 2008: Heartworm disease in animals and humans. Adv Parasitol 66: 193-285

Penezić A, Selaković S, Pavlović I, Ćirović D 2014: First findings and prevalence of adult heartworms (Dirofilaria immitis) in wild carnivores from Serbia. Parasitol Res 113: 3281-3285

Spratt DM 2015: Species of Angiostrongylus (Nematoda: Metastrongyloidea) in wildlife: a review. Int J Parasitol Parasites Wildl 4: 178-189

Steeb S, Hirzmann J, Eskens U, Volmer K, Bauer C 2014: Lungenwurm-infektionen bei der Europäischen wildkatze. Kompakt Vet 3: 9

Traversa D, Di Cesare A 2014: Cardio-pulmonary parasitic nematodes affecting cats in Europe: unraveling the past, depicting the present, and predicting the future. Front Vet Sci 1: 11

Traversa D, Lepri E, Veronesi F, Paoletti B, Simonato G, Diaferia M, Di Cesare A 2015: Metastrongyloid infection by Aelurostrongylus abstrusus, Troglostrongylus brevior and Angiostrongylus chabaudi in a domestic cat. Int J Parasitol 45: 685-690

Venco L, Genchi M, Genchi C, Gatti D, Kramer L 2011: Can heartworm prevalence in dogs be used as provisional data for assessing the prevalence of the infection in cats? Vet Parasitol 176: 300-303 
Plate III

Gherman C. M. et al.: Co-infection with ... pp. 303-306

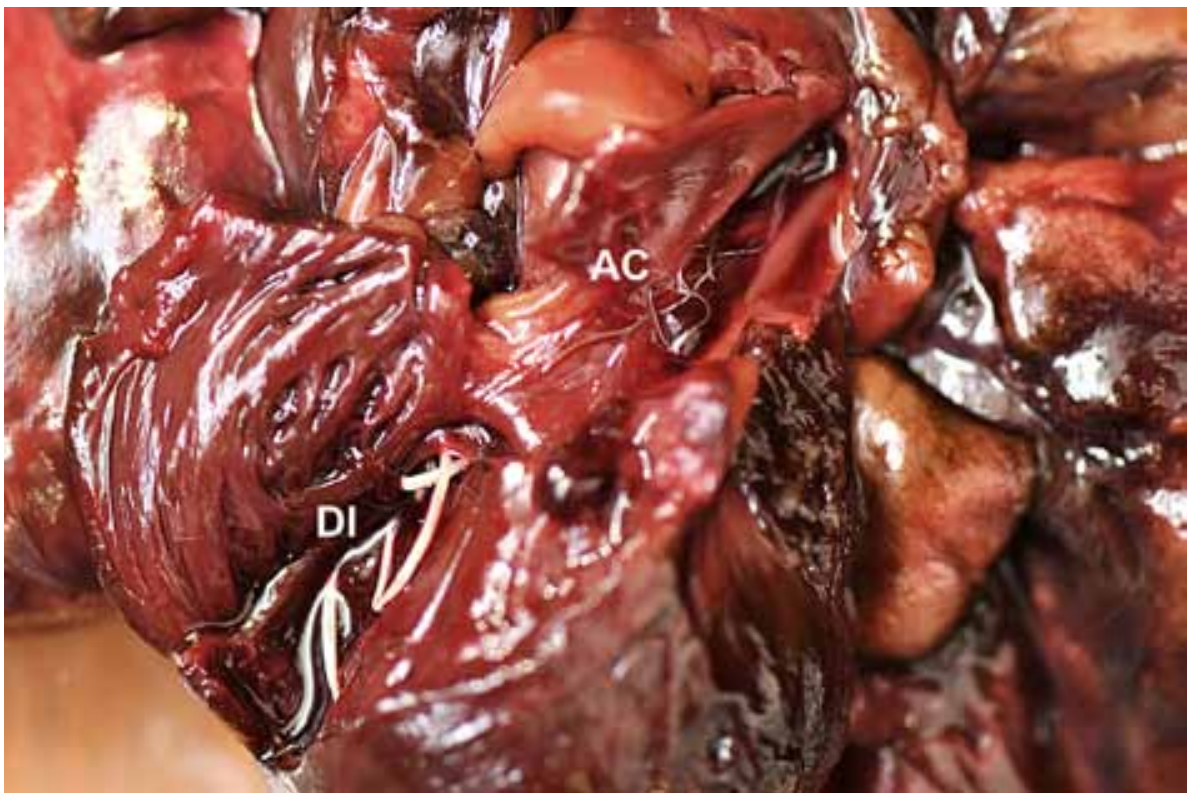

Fig. 1. Co-infection with Angiostrongylus chabaudi (AC) and Dirofilaria immitis (DI) in the heart of a wildcat 